\title{
A EDUCAÇÃO E A FÁBRICA DE CORPOS: A DAN ÇA NA ESCOLA
}

\author{
M Árcia Strazzacappa*
}

\begin{abstract}
RESU M 0: 0 movimento corporal semprefoi dentro do espaço escolar uma moeda de troca. A imobilidade física funciona como punição ea liberdade de se movimentar como prêmio. Estas atitudes evidenciam queo movimento ésinônimo deprazer eaimobilidade, dedesconforto. $M$ as se é através do movimento que 0 indivíduo se manifesta, que indivíduosiremosformar seimpedimossua expressão?0 presentetexto abordará a questão da introdução da dança no espaço escolar, rel atando erefletindo sobreo trabal ho queédesen volvido no curso de Licenciatura em D ança da U nicamp epartilhando das experiências de professores da rededeensino quefizeram o curso de "atividades corporaisartísticaspara professores da educação formal" em Tupã (SP).
\end{abstract}

Palavras-chave: dança, corpo, educação, formação professor, arteeducação

\section{Introdução: 0 corpo no espaço escolar}

0 indivíduo ageno mundo através deseu corpo, maisespecificamente através do movimento. É o movimento corporal que possibilita às pessoas se comunicarem, trabalharem, aprenderem, sentirem o mundo e serem sentidos. No entanto, há um preconceito contra o movimento. Solange Arruda, na introdução de seu livro Arte do movimento, afirma que "é mais chic, educado, correto, civilizado e intelectual permanecer rígido. 0 sadultos, em sua maioria, não se movimentam e reprimem a soltura das crianças." I sso começa em casa e se prolonga na escola.

Embora conscientes de que o corpo é o veículo através do qual 0 indivíduo se expressa, o movimento corporal humano acaba ficando dentro

* Professora do D epartamento de M etodologia do Ensino da Faculdade de Educação da U nicamp e D outora em Estudos Teatrais e Coreográficos (U niversidade de Paris). E-mail: m.strazzacappa@uol.com.br 
da escola, restrito a momentos precisos como as aulas de educação física e 0 horário do recreio. $N$ as demais atividades em sala, a criança deve permanecer sentada em sua cadeira, em silêncio e olhando para a frente. Ciro Giordano Bruni afirmava a esse respeito que "virou quase regra estabelecer entre a arte e a ciência uma lastimável distinção: a primeira se aprende como uma atividade lúdica e a segunda, de uma maneira séria e constrangedora." ${ }^{2}$ Sua crítica não se fixa apenas na questão da ausência do lúdico nas disciplinas científicas da escola, mas também na ausência de seriedade nas disciplinas artísticas, comportamento que tende a acentuar a visão de que o ensino de arte é supérfluo.

A noção de disciplina na escola sempre foi enten dida como "nãomovimento". As crianças educadas e comportadas eram aquelas que simplesmente não se moviam. 0 modelo escolar-militar da primeira metade do século XX era aplicado desde o momento em que a criança chegava na escola. As filas por ordem de tamanho para se dirigirem às salas de aula, o levantar-se cada vez que o diretor ou supervisor de ensino entrava na sala etc. Atualmente, são raros os estabelecimentos escolares que mantêm este tipo de atitude, encontrado ainda apenas em escolas de cunho religioso e em algumas escolas públicas de cidades pequenas do interior do estado. $N$ as escolas da rede pública das grandes cidades, esta realidade já não existe. A pesar da ausência destas atitudes disciplinares, a idéia do não-movimento como conceito de bomcomportamento prevalece. M uitas escolas aboliram as filas e os demais símbolos de respeito a diretores e professores; no entanto, foram criadas outras maneiras de se limitar o corpo.

0 movimento corporal sempre funcionou como uma moeda de troca. Se observarmos brevemente as atitudes disciplinares que continuam sendo utilizadas hoje em dia nas escolas, percebemos que não nos diferenciamos muito das famosas "palmatórias" da época de nossos avós. Professores e diretores lançam mão da imobilidade física como punição e da liberdade de se movimentar como prêmio. Constantemente, os alunos indisciplinados (lembrando que muitas vezes o que define uma criança indisciplinada é exatamente o seu excesso de movimento) são impedidos de realizar atividades no pátio, seja através da proibição de usufruir do horário do recreio, seja através do impedimento de participar da aula de educação física, enquanto que aquele que se comporta pode ir ao pátio mais cedo para brincar. Estas atitudes evidenciam que o movimento é sinônimo de prazer e a imobilidade, de desconforto. 
O s cursos de Educação Artística, cujo caráter "menos formal" poderiam possibilitar uma maior mobilidade das crianças em sala de aula, tendem a priorizar ostrabalhosem artes plásticas (desenho, pintura eal gumas vezes escultura), atividadesonde 0 aluno acaba tendo de permanecer sentado. Embora a LD B 9394/96 garanta o ensino de Arte como componente curricular obrigatório da Educação Básica representado por várias linguagens - música, dança, teatro e artes visuais - , raramente a dança, a expressão corporal, a mímica, a música e o teatro são abordados, seja pela falta de especialistas da área nas escolas, seja pelo despreparo do professor.

A pesar destas atitudes estarem muito presentes, algumas experiências (que caminham exatamente no sentido oposto) têm nos mostrado o quanto o movimento pode contribuir para se criar no espaço escolar um outro ambiente. A introdução de atividades corporais artísticas na escola, ou seja, a realização de trabalhos de dança-educativa ou dança-expressiva, como são comumente chamadas (embora não goste muito destes nomes, afinal, toda dança é educativa e expressiva), tem mudado significativamente as atitudes de crianças e professores na escola. A dança no espaço escolar busca o desenvolvimento não apenas das capacidades motoras das crianças e adolescentes, como de suas capacidades imaginativas ecriativas. As atividades de dança se diferenciam daquelas normal mente propostas pela educação física, pois não caracterizam o corpo da criança como um apanhado de alavancas earticulações do tecnicismo esportivo, nem apresentam um caráter competitivo, comumente presente nos jogos desportivos. Ao contrário, 0 corpo expressa suas emoções e estas podem ser compartilhadas com outras crianças que participam de uma coreografia de grupo.

\section{A dançaeseusdiferentesfins}

Q uando se fala em dança na escola, milhares de imagens começam apovoar nossasmentes. Afinal, dequedançaestamosfalando? Ao chegarmos nas instituições, costumamos interrogar as crianças e os adolescentes sobre sua compreensão de dança. É interessante observar que, se há alguns anos atrás, a primeira imagem que vinha à mente destes jovens era a figura da bailarina clássica nas pontas dos pés, hoje essa imagem (embora ainda presente) já está sendo substituída por outras trazidas pela mídia. As respostas variam entre as dançarinas do "T chan" e al gumas pop stars norteamericanas (nota-se a predominância da figura feminina). Q uando interrogados, então, sobre o que querem aprender numa aula de dança, as respostas se multiplicam, indo do ballet clássico às danças de rua. 
N o próprio curso de Licenciatura em $D$ ança da U nicamp também encontramos diferentes expectativas por parte dos alunos. Uns têm interesse direto em trabalhar a dança nas escolas da rede de ensino, logo, a dança dita "educativa". 0 utros, em trabal har em escolas especializadas como conservatórios e academias, com técnicas de dança específicas para a formação do profissional. $\mathrm{H}$ á ainda os que preferem trabalhar $\mathrm{O}$ aspecto social da dança, ou seja, a dança como atividade de reinserção social em programas de apoio a pessoas desfavorecidas. Todas estas expectativas não podem ser ignoradas. Elas revelam a própria abrangência da área de dança e temos, assim, de aprender a lidar com elas, sem se perder de vista 0 objetivo das licenciaturas, ou seja, habilitar o futuro profissional para trabalhar no ensino fundamental e médio.

J acqueline R obinson, ${ }^{3}$ bailarina e educadora francesa, elaborou um diagrama onde indica de forma clara a gênese e as diferentes aplicações da dança no mundo contemporâneo.

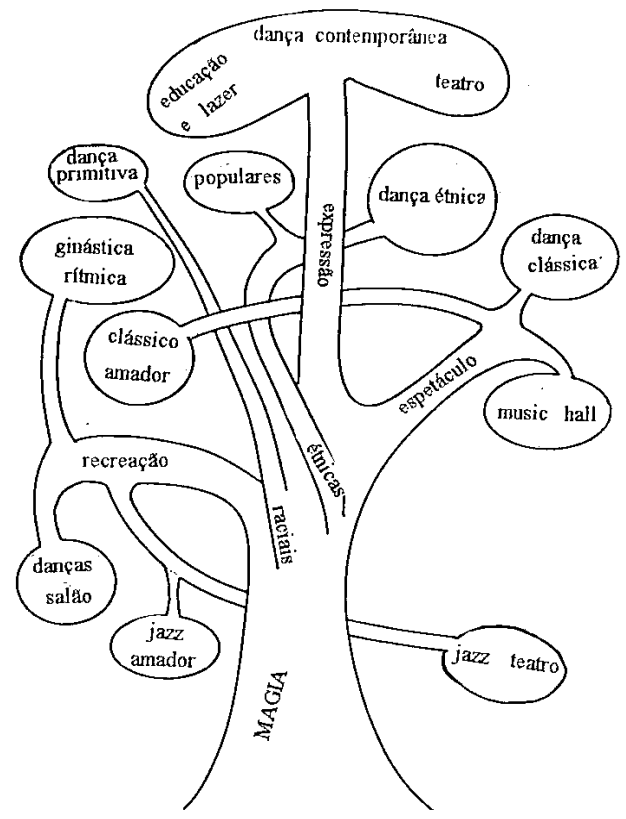

Toda dança, não importa qual a estética que lheé inerente, surge da profundeza do ser humano, ou, como Robinson nomeou, surge da "magia" eadquirediversas funçõesa partir detrês motivações principais: aexpressão, o espetáculo e a recreação (ou jogo). 
A expressão é a motivação mais significativa da dança, sendo representada na árvore de Robinson como o tronco principal. É nesse tronco que se situam o teatro, a dança contemporânea, a educação e o lazer. Ao redor deste tronco principal, com uma bifurcação para a recreação e outra para o espetáculo, estão as danças populares. Robinson fez esta divisão, uma vez que estas manifestações podem ser a expressão de uma comunidade, como rito ou jogo, e ainda serem exploradas através de espetáculos. $H$ á ainda as manifestações populares consideradas "puras", ou seja, que não perderam seu caráter original de rito, que Robinson localizou num tronco à parte, entre a recreação e a expressão, chamando-o de "danças primitivas", na falta de uma melhor expressão para intitulá-las.

No tronco recreação encontramos as danças amadoras, as danças de salão, a ginástica rítmica e o jazz, todas técnicas praticadas por indivíduos sem interesseprofissional. Percebe-sequeo jazz tevesua origem narecreação, profissionalizando-se posteriormente, ao en contrar seu caráter espetacular. 0 inverso aconteceu com adançaclássica. D eorigem estritamenteespetacular e profissional, com o decorrer dos anos ganhou adeptos amadores que buscam essarígidatécnica como complemento da educação corporal formal.

N uma tentativa de atualizar esta árvore, poderíamos acrescentar muitas outras danças: Algumas danças populares brasileiras, como o forró, o samba, a lambada e recentemente 0 axé, que também conquistaram os espaços dos cursos de dança de salão ao lado das imortais valsa, tango e bolero. As danças provenientes de regiões e países específicos, como a dança do ventre, a dança flamenca, o sapateado americano eirlandês (tão em voga atual mente) eas danças de rua (ou street dance), poderiam ser introduzidas como um gal ho queseinicianas expressõesculturais(folclóricas) eseramifica tanto parao campo profissional do espetáculo, quanto paraaáreaderecreação (amadora). U m bom exemplo são as danças de rua. Elas tiveram origem nos guetos negros norte-americanos, como forma de protesto, e ganharam adeptosno mundo todo. Como o rap, o funk eo break, muitas dessas danças já saíram das ruas e invadiram as academias e palcos teatrais.

$N$ este diagrama, fica evidente a diferenciação queéfeita entre o fazer amador, o profissional, o educativo e as manifestações culturais. M as seria o ensino de dança um só para todos? No curso de Licenciatura em D ança, deixamos em aberto a opção estética. 0 queimportanão éalinha escolhida, mas como através dela podese trabal har os elementos que consideramos importantes para o desenvolvimento integral do indivíduo na escola. 
N ão sem problemas...

Em instituições ondea dança começou a ser trabal hada, professores e diretores sentiram a diferença de comportamento de seus alunos. A começar pelo número de faltas, que diminuiu razoavelmente. A participação dos alunos em outras atividades promovidas pela escola (festas, semanas culturais e científicas, gincanas etc.) começou a ser mais efetiva. D e maneira geral, os professores são unânimes ao afirmar que o interesse do aluno pelo ensino melhorou, como se, através das atividades de dança na escola, 0 aluno tivesse reencontrado o prazer de estar nesta instituição.

N o entanto, tudo isso não se deu sem problemas. A experiência com os alunos estagiários da Licenciatura em $D$ ança da U nicamp tem mostrado que, se a dança está aos poucos conquistando um espaço diferenciado dentro da formação escolar fundamental, muitas barreiras ainda têm que ser derrubadas. A primeira delas é a receptividade dos própriosprofessores daescola. Algunstendem a "menosprezar" o trabal ho, considerando a dança um "luxo" de menor importância no conjunto das disciplinas oferecidas pelo currículo. Estes professores acabam assumindo posturas que dificultam o trabalho dos estagiários, como, por exemplo, intitularem o trabalho "aula de recreação". Ao ouvirem esta nomenclatura, os al unos saem correndo dispersos para o pátio e ninguém consegue mais reagrupá-los para a aula. Alguns professores que aprovam a iniciativa, por outro lado, reclamam que as crianças ficam mais agitadas nos dias em que há atividades de dança. Assim, para "acalmar" a classe, acabam usando a famosa "chantagem": ou vocês ficam quietos e prestam atenção, ou não irão para a aula de dança. A segunda barreira diz respeito a um outro tipo de preconceito, desta vez não do professor, mas do próprio aluno. Em algumas escolas, os estagiários são obrigados a chamarem 0 trabal ho de "expressão corporal", pois se 0 nome "dança" aparece, muitos meninos se recusam a participar da atividade por não serem "mulherzinhas" [sic].

$\mathrm{N}$ o trabal ho com adolescentes, a realidade é outra. Q uando interrogados sobre o que é a dança ou sobre qual dança gostariam de aprender na escola, a maior parte dos jovens (sobretudo os rapazes) opta pelas danças de rua ${ }^{5}$ (rap, funk, break). Apesar destas danças possuírem uma movimentação considerada agressiva pelos adultos, el as fazem parte do universo destes jovens. A violência é um dos temas mais explorados. 
Eles simulam lutas, fazem gestos obscenos, criam na execução da coreografia grupos que se enfrentam etc. No entanto, é interessante notar que tudo isso é a "ritualização" da violência, não a violência em si. Há exemplos de grupos de jovens que saíram da marginalidade através das danças de rua. Como eles mesmo afirmam: "através da dança a gente 'canaliza' nossa agressividade e, assim, não precisamos mais ser violentos com ninguém". ${ }^{6}$ D entro da dinâmica das danças de rua, para se aprender uma coreografia, os participantes devem prestar muita atenção para "pegar os passos" e depois "aprender o estilo". Como as coreografias são feitas por todos os partici pantes do grupo e ao longo de vários encontros, faltas não podem acontecer, senão perde-se uma parte das seqüências (que são complexas e num ritmo acelerado) e atrapal ha-se o conjunto final. Assim, a disciplina e a responsabilidade são compreendidas, aprendidas e incorporadas no dia a dia destes jovens. A pesar de todos dançarem os mesmos movimentos, há momentos onde um se destaca, realizando sua "improvisação". É nesta hora que o jovem tem a oportunidade detrabalhar a sua individualidade, mostran do o seu "estilo" pessoal e sua virtuosidade, visto que é no solo que o jovem realiza as acrobacias mais complexas.

\section{Compartilhando experiências- oficinas}

Em junho passado, aproveitando minha visita à Tupã para participar do I T upã-D ança, ${ }^{7}$ ministrei uma oficina "teórico-prática" de atividades corporais artísticas para professores do ensino formal. 0 curso contou com a participação de professores de educação física, educação artística, línguas, dança, e professores de préescola. $\mathrm{H}$ avia tomado o cuidado de intitulá-la oficina "teórico-prática" (embora não concorde com esta dicotomia teoria/prática, nem com esta expressão que junta, separando), com o intuito de deixar claro que haveria uma parte prática e que todos, sem exceção, deveriam participar de todas as atividades propostas.

Alguns poucos professores participantes esperavam receber fórmulas préfabricadas ou receitas prontas de como trabalhar a dança no espaço escolar. Tinham a expectativa de aprender alguns "passinhos" (como disseram) ou mesmo algumas coreografias para poderem, mais tarde, transmitir a seus alunos, seja na festa junina, que se aproximava, seja nas comemorações folclóricas do mês de agosto. N ormalmente, professores com este tipo de expectativa costumam ficar apavorados cada vez que chega uma data comemorativa e que se vêem "obrigados" a preparar algum 
evento com as crianças. Eles não acreditam em seus potenciais criativos e preferem copiar fórmulas prontas. No entanto, havia deixado claro que este não era o objetivo da oficina. N ão havia "prato-feito" para "prontaentrega", onde basta telefonar que a comida chega em casa, sem trabalho algum. M uito pelo contrário, todos teriam de erguer as mangas, pôr a mão na massa e se sujar para "aprender fazendo". 0 objetivo da oficina era proporcionar aos professores da rede de ensino a oportunidade de aprenderem a "pensar com o corpo". E como fazer isso senão através do próprio movimento?

As atividades práticas se baseavam em elementos trabalhados em aulas de dança. N um primeiro momento, focamos o desenvolvimento da consciência corporal utilizando os conceitos oriundos da educação somática. Grosso modo, a educação somática ${ }^{8}$ é entendida como atividades onde o corpo étrabalhado de modo a integrar todos os aspectos que o compõem: social, espiritual, psíquico, físico etc. Assim, temos as práticas como astécnicas deAlexander, Feldenkrais, Body-M ind-C entering, Eutonia, Fundamentals ${ }^{\circledR}$, entre outras. C omo representantes da vertente brasileira de educação somática, temos o trabalho de K lauss V ianna e de J osé Antonio Lima. N um segundo momento da oficina, trabalhamos a criação coreográfica, através da exploração espacial, baseando-nos nos preceitos de Rudolf von Laban (1879-1958). (N ão iremos aqui discorrer longamente sobre o trabalho desenvolvido por este reformador do movimento, visto que outros autores ficaram incumbidos de fazê-lo. No entanto, não podemos deixar de falar sobre ele, pois quando se pensa em dança-educativa, seu nomeéum dosmaiscitados). Estecoreógrafo austrohúngaro e estudioso do movimento revolucionou a maneira de se pensar o corpo em movimento. Ele desenvolveu um método de análise do movimento, definindo os elementosqueo compõem. Elaborou igualmente um método de escrita em dança, a Labanotiation. Seus trabalhos têm diferentes aplicações que vão da educação da dança, da criação coreográfica ao trabal ho terapêutico. Seu trabal ho foi introduzido no Brasil por M aria D uschenes. ${ }^{9}$

Acreditava-se que nesta oficina seria muito mais salutar ensinar os professores a pensar com o corpo, que ficar discutindo sobre o corpo, como se este fosse um objeto à parte de nós mesmos. Ao mexer com o corpo, ao criar, ao se expressar, estes professores estavam adquirindo informações, sensações que seguramente iriam, mais tarde, nutrir e enriquecer suasanálises ediscussõesteóricas. Acreditava-se que, numa oficina, deveria oferecer-Ihes 0 
que não encontrariam em livros: a oportunidade de tocar e ser tocado, de expressar e ser visto, de falar e ouvir com o corpo todo. As atividades proporcionariam explorações sensoriais. 0 grupo de participantes, a princípio tímido, foi aos poucos se soltando e ao final se entregou completamente ao jogo, explorando o espaço, dançando e cantando.

G ostaria de ressaltar o comentário de uma professora da rede pública aposentada, Gilcélia, quetrabal haatual menteno setor privado. Estatentou escapar de uma das atividades propostas que consistia em ser carregado pelo grupo em duas situações distintas: com o corpo contraído e com 0 corpo relaxado. A pesar de sua tentativa de fuga, não teve escapatória e foi logo carregada. Q uando se esticava no chão, aguardando ser levantada, não parava de exclamar: Vocêsnão vão conseguir!Vocêsnão vão meagüentar! Q ual não foi o seu espanto (e também do grupo) ao perceber que estava a dois metros do chão, segura por dezenas de mãos que a suspenderam acimado nível desuas cabeças. A o final do trabal ho, emocionada, percebeu o quanto havia sido importante participar do exercício, pois percebera que na verdade a imagem que tinha de si própria não correspondia à realidade. ${ }^{10}$ Sentiu-se mais leve e feliz. Seguramente, esta sensação lhe ensinou muito maisefoi-Ihemuito maisimportantequequal quer discussão teórica a respeito dos benefícios do desenvolvimento de um trabal ho corporal dentro da escola.

O s professores, ao sentirem no corpo estas descobertas, podem compreender melhor o que se passa nos corpos de seus alunos, crianças ou adolescentes. Ao experimentarem o prazer do movimento e os benefícios que estes trazem, tanto para o físico quanto para o mental, podem ver com outros ol hos estas atividades na escola. E o mais importante, ao invés de simplesmente "memorizarem" passos coreográficos, estes professores terminaram a oficina com um instrumental muito maior para realizarem suas próprias criações.

\section{A educação eafábrica decorpos}

A dança na escola deve ultrapassar a idéia de ser voltada apenas à criança e ao adolescente. A pós esta experiência com os professores da rede de ensino de Tupã, ficou mais evidente que trabal har com os professores é importante não apenas para a formação destes (e para o bem estar dos mesmos, evidentemente), mas também que o corpo do professor funciona como modelo para o aluno. 
É inerente ao ser humano sua capacidade de imitação. A criança aprende através da reprodução dos gestos dos adultos. $M$ arcel $M$ auss, sociólogo e antropólogo francês e um dos primeiros a classificar as técnicas do corpo, ${ }^{11}$ concluiu que todas as ações humanas, desde a mais simples posição deitada (simples entendido como mínimo esforço físico solicitado) até as ações mais elaboradas, como nadar (que requer um treinamento específico), são técnicas adquiridas por meio da imitação. 0 adulto faz e a criança copia.

0 ensino da dança e das demais artes da tradição oral é feito por meio da observação e reprodução do observado. $\mathrm{N}$ a maioria das técnicas sistematizadas e codificadas, o professor faz e 0 al uno imita. Poderíamos pensar que no caso da dança na escola - onde se trabal ha mais a exploração e a criação do próprio aluno que o aprendizado de passos específicos - a imitação não está presente. No entanto, essa idéia é equivocada. Alguns estagiários ficavam preocupados com a questão de dar exemplos de movimentação ou deservir demodelo. N o entanto, elesprópriosperceberam que, muitas vezes, em suas criações, as crianças reproduziam gestos oriundos de grupos vistos na televisão ("dança da garrafa", da "bundinha" etc.). Seos estagiários não são e não querem assumir um papel de modelo, a mídia o é atodo momento. Cabeagora a cada um refletir sobrequal model o considera mais interessantee, sobretudo, trabalhar com as criançaso desenvolvimento do ol har crítico.

Temosqueressaltar quenão apenasa movimentação servedemodelo. A própria postura também é objeto de imitação. Lembro-me de um professor de dança que vivia corrigindo a postura de seus alunos e que não sabia maiso quefazer, poiselesacabavam semprevoltando àquelaindesejada. U m dia, ele veio me procurar na tentativa de solucionar esta questão. "0 que fazer? Q ue tipo de exercício posso estimular?" - perguntava. Ao vêlo, minha resposta foi clara e curta: "Corrija vocêa sua própria postura que os alunos, aos poucos, corrigirão a deles." N ão adianta o professor corrigir insistentemente a postura dos al unos se 0 que Ihes fala mais forte não é a palavra (verbo) e sim o modelo vivo (corpo).

D esenvolver um trabalho corporal com os professores teria uma dupla função: despertá-los para as questões do corpo na escola e possibilitar a descoberta e desenvoltura de seus próprios corpos, lembrando que, independentedasdisciplinasquelecionam (português, matemática, ciências etc.), seus corpos também educam. É comum percebermos pessoas que 
adquirem a maneira de gesticular daquele com quem convive cotidianamente. Basta pensarmos nos gestos que "herdamos" de nossos pais ou observarmos velhos casais. $\mathrm{H}$ á a tendência de se reproduzir a mesma movimentação de cabeça, adquirir o mesmo "tic" ou assumir a mesma postura. Assim, diante de uma classe de crianças, queiramos ou não, somos sempre um modelo para a imitação pela mímesis. D essa forma, acredito que os cursos de formação de professores, seja a graduação em Pedagogia ou as demais licenciaturas específicas, deveriam pensar com seriedade no oferecimento de disciplinas de cunho artístico corporal.

Fica claro que a questão da educação corporal não é de responsabilidadeexcl usiva das aulas de educação física, nem de dança ou de expressão corporal. 0 corpo está em constante desenvolvimento e aprendizado. Possibilitar ou impedir o movimento da criança e do adolescente na escola; oferecer ou não oportunidades de exploração e criação com o corpo; despertar ou reprimir o interesse pela dança no espaço escolar, servir ou não de modelo... de uma forma ou de outra, estamos educando corpos. Nós somos nosso corpo. Toda educação é educação do corpo. A ausência de uma atividade corporal também é uma forma de educação: a educação para o não-movimento - educação para a repressão. Em ambas as situações, a educação do corpo está acontecendo. 0 que diferencia uma atitude da outra é o tipo de indivíduo que estaremos formando. C abe agora a cada um de nós fazer a reflexão.

\section{ThE EDUCATION AND THE BODY'S FACTORY: D ANCE IN SCHOOL}

ABST RACT : For a long time, body's movement at school has been treated as a prize or a punishment. Physical immobility works as a punishment and freedom of movement works as a prize. These procedures show that to move is a pleasure and to stay still is uncomfortable. But, if movement is the way that people express themselves, what kind of peopleare we educating if we repress their expression?T his article discuss the introduction of dancestudies in school, based on thework is being developed with thestudents of the $D$ anceD epartment at theStateU niversity of $C$ ampinas. I t also shows theexperience of theteacherswho participated in aworkshop "artistic body'sactivitiesfor teachers of basic education" realized in Tupã(SP).

Keywords: dance, body, education, teacher education, art-education. 


\section{N otas}

1. ARRUD A, Solange. A arte do movimento. São Paulo: PW Editores Associados, 1988, p. 11.

2. BRUN I, Ciro Giordano. Pour une danse d'éveil et d'initiation, le discernement de la distance, In: L'enseignement de la danse et après!, Rencontres dans les U niversités Paris V e Paris VIII, Paris: Germs, 1998, p. 78.

3. RO BIN SO N, Jacqueline. Lelangagechorégraphique. Paris: Vigot, 1978.

4. Sobre a discussão do gênero na construção social, ver SO UZA, E.S. e ALT M AN N , H . M eninos e meninas: expectativas corporais e implicações na educação física escolar, Cadernos C edes $n$ o 48, 1999.

5. Cf. edição especial da Revista Caros Amigos, São Paulo, set. 1998.

6. Comentário de um dos integrantes do grupo Guardiões do RAP, de 0 urinhos/SP, junho 2000.

7. I T upã-dança - evento promovido em parceria pela Secretaria de Estado da Cultura, Secretaria M unicipal de Educação e Cultura (Sra Joana Schelini) e Academia M aria Cristina Sismeiro Dias, 16 e 17 de junho de 2000.

8. A este respeito, ver os artigos do Caderno Especial "Estudos do Corpo", organizado por Christine Greiner, do GIPE-CIT, UFBA (1999) e os números 28 e 29 da Revista N ouvelles de Danse, Bruxelas, 96/97.

9. Sobre M aria D uschenes, ver o capítulo "As mães da modernidade" no livro Dança moderna, de Cássia N avas e Lineu D ias, São Paulo: Secretaria M unicipal de Cultura de São Paulo, 1992.

10. Cf. M oshe Feldenkrais, 0 poder da auto-transformação, São Paulo: Summus, 1978. Ele afirmava que nós agimos de acordo com nossa auto-imagem. $\mathrm{N}$ a verdade temos um potencial de movimento muito maior do que utilizamos normalmente. $\mathrm{No}$ entanto, a imagem que temos de nós mesmos cria barreiras que impedem a exploração total de nossas capacidades. Ver também, do mesmo autor: C onsciência pelo movimento (1989).

11. Ver M arcel M auss, Les techniques du corps, Journal de Psychologie, XXXII, n 3-4, 15 mars/15 avril, 1936, publicado posteriormente em Sociologi e et Anthropologie, Paris: PU F, 1966.

\section{Referências bibliográficas}

AGE du corps, maturité de la danse. Actes de la table ronde organisée par le C ratèreT héâtre d'Alès, le 13 avril, 1996.

ARRU D A, Solange. Artedo movimento. São Paulo: PW G ráficos eEditores Associados Itda., 1988.

BERTRAN D, M onique \& DUM ONT, M athilde. Expression corporelle M ouvement et pensée. Paris: LibrairiePhilosophiqueJ. Vrin, 1979.

DIAS, Linneu \& N AVAS, Cássia. Dança moderna. São Paulo: Secretaria M unicipal deCultura deSão Paulo, 1992.

D U PUY, D ominique. Ce que dit le maître. In: Expérience et Transmission, Colóquio em Clermont-Ferrand, junho 1998. 
. Le corps du maître. In: ALSAN, 0 dette (dir.). Le corps en jeu. Paris: Edição do CN RS, 1991.

EXPÉRIEN CE et transmission. Actes du colloque de danse, Festival de la pensée, du 22 au 27 juin 1998, Brut de Bréton, Clermont-Ferrand, 1998.

FELDEN KRAIS, M oshe. Awareness through movement. San Francisco: H arper Collins Publishers Inc., 1972. (Em português: Consciência pelo movimento. São Paulo: Summus, 1977).

. L'Energie et bien-être par le mouvement. Trad. de Lisette Rosenfeld. Paris: Edition D angles, 1996.

. 0 Poder da autotransformação. Trad. de D enise Bolanho. São Paulo: Summus, 1994.

FUX, M aria. D ança, uma experiência de vida. São Paulo: Summus, 1986. GO D ART, H ubert. A propos des théories sur le mouvement. M arsyas, 16, 1992, p. 19-23.

. Le mouvement: $\mathrm{D}$ e la décomposition à la recomposition. $\bar{M}$ arsyas, 25, 1993.

HERN AN DEZ, M árcia. "O corpo em-cena". D issertação de mestrado, D epartamento de M etodologia do Ensino, Faculdade de Educação/U nicamp. Campinas, 1994.

LABAN, Rudolf. M odern educational dance. Londres: M acD onald and Evans, 1975.

.T he mastery of movement. Revised by Lisa U IImann, Plymouth: N orthcoteH ouse, 1992. (Em português: 0 domínio do movimento. Trad. de Anna M aria de Vecchi e M aria Silvia M ourão N etto, São Paulo: Summus, 1981).

LAU N AY, I sabelle. A la recherched'une dansemoderne. Rudolf Laban - M ary W igman. Paris: Librairie de la D anse/Art N omade, Chiron, 1996.

L'EN SEIG N EM ENT de la danse et après! Rencontres dans les Universités Paris V et Paris VIII, Paris: Germs, jan. 1998.

LIM A, J oséAntonio, "M ovimento Corporal - A práxis da corporalidade". D issertação de M estrado, D epartamento de Filosofia e H istória da Educação, Faculdade de Educação/U nicamp, 1994. 
LO UPPE, Laurence. Poétique de la danse contemporaine. Bruxelles: Contredanse, 1997.

. Etats de corps perdus: Le voyage historique. 10 - Revue InternationaledePsychanalyse, 5, 1994.

M ARSYAS. Publicação do Institut Pédagogique de la M usique et de la D anse C ontemporaines (IPM C), Paris.

M AUSS, M arcel. Letechniquesdu corps. Journal dePsychologie, XXXII, no 3-4, 15 mars/15 avril, 1936. Comunicação apresentada à Société de Psychologieem 17 maio 1934, In: Sociologi eet Anthropologie, PU F, 1966, p. 370-371.

N OU VELLES de D anse. Contredanse, Bruxelles, Belgique (Sobretudo os números especiais: "D ossier autour de Rudolf Laban", Nouvelles de danse, no 25, outono/1995; "L'intelligence du corps" ( $1^{\mathrm{a}}$ Parte), Nouvelles de danse $n$ ㅇ 28, verão/1996; "L'intelligence du corps" ( $2^{\mathrm{a}}$ Parte), N ouvelles de danse $n-29$, outono/1996.

OSSO N A, Paulina. A educação pela dança. São Paulo: Summus, 1988.

PO RCH ER, Louis (org.). Educação artística: Luxo ou necessidade? Trad. de Yan M ichalski, São Paulo: Summus, 1982.

PRADIER, Jean-M arie. Le public et son corps: Éloge des sens. Thêatrel Public, № 120, 1994.

RO BIN SO N , Jacqueline. Lelangagechorégraphique Paris: Vigot, 1978.

. L'enfant et la dance. Paris: AAA Siegfried, 1993.

RO U Q UET, O dile (org.). Les techniques d'analyse du mouvement et le danseur. Paris: Recherche en mouvement, 1985.

RO USIER, Claire (org.). H istoires de corps - A propos de la formation du danseur. Paris: Cité de la M usique, 1998.

SLATER, Wendy. Teaching modern educational dance. Plymounth: N orthcote H ouse, 1976.

ST OKOE, Patrícia \& HARF, Ruth. Expressão corporal na pré escola. São Paulo: Summus, 1987.

ST RAZZACAPPA-H ERN AN D EZ, M árcia. "Fondements et enseignement des techniques corporelles des artistes de la scène dans I'Etat de São 
Paulo, Brésil, au Xxème siècle". Tese de D outorado em Estudos Teatrais e C oreográficos, U niversité de Paris VIII, Saint D enis. França, 2000.

SO U SA, Eustáquia e ALT M AN N , H elena. M eninos e meninas: Expectativas corporais e implicações na educação física escolar. Cadernos Cedes no 48, Campinas: Cedes, 1999.

VIAN N A, Klauss. A dança. São Paulo: Siciliano, 1991. 